\title{
Design and development of solar power-assisted manual/electric wheelchair
}

\author{
Chi-Sheng Chien, MD; ${ }^{1}$ Tung-Yung Huang, PhD; ${ }^{2}$ Tze-Yuan Liao, PhD; ${ }^{3}$ Tsung-Yuan Kuo, PhD; ${ }^{2 *}$ Tzer-Min \\ Lee, $\mathbf{P h D}^{4}$ \\ ${ }^{1}$ Department of Orthopedics, Chimei Foundation Hospital, and Department of Electrical Engineering, Southern Tai- \\ wan University of Science and Technology, Tainan, Taiwan; ${ }^{2}$ Department of Mechanical Engineering, Southern Taiwan \\ University of Science and Technology, Tainan, Taiwan ${ }^{3}$ Department of Materials Engineering, National Cheng Kung \\ University, Tainan, Taiwan; ${ }^{4}$ Institute of Oral Medicine, National Cheng Kung University, Tainan, Taiwan
}

\begin{abstract}
Wheelchairs are an essential assistive device for many individuals with injury or disability. Manual wheelchairs provide a relatively low-cost solution to the mobility needs of such individuals. Furthermore, they provide an effective means of improving the user's cardiopulmonary function and upperlimb muscle strength. However, manual wheelchairs have a gross loss of mechanical efficiency, and thus the risk of user fatigue and upper-limb injury is increased. Electric-powered wheelchairs reduce the risk of injury and provide a more convenient means of transportation. However, they have a large physical size and are relatively expensive. Accordingly, the present study utilizes a quality function deployment method to develop a wheelchair with a user-selectable manual/electric propulsion mode and an auxiliary solar power supply system. The auxiliary solar power supply increased the travel range of the wheelchair by approximately $26 \%$ compared with that of a wheelchair powered by battery alone. Moreover, the wheelchair has a modular design and can be disassembled and folded for ease of transportation or storage. Overall, the present results suggest that the proposed wheelchair provides an effective and convenient means of meeting the mobility needs of individuals with mobility difficulties.
\end{abstract}

Key words: disassemble, electric operation mode, electric wheelchair, manual operation mode, manual wheelchair, mobility assistive device, power-assisted wheelchair, QFD, quality function deployment method, solar power.

\section{INTRODUCTION}

The elderly face many physical challenges, including nerve and muscular degeneration, reduced motor function and balance, impaired mobility, and so on. Thus, the wheelchair is considered an essential assistive device for improving the mobility, living quality, and dignity of the elderly and those with mobility difficulties arising from physical disabilities, accident-related injuries, and so on [1]. Generally speaking, existing wheelchairs can be categorized as either manual, electric-powered, or power-assisted depending on their mode of propulsion. Traditional manual wheelchairs (MWs) induce a greater oxygen consumption and a higher respiratory exchange ratio and are therefore

Abbreviations: $\mathrm{CG}=$ center of gravity, $\mathrm{CR}=$ customer requirement, $\mathrm{DC}=$ direct current, $\mathrm{DR}=$ design requirement, $\mathrm{EPW}=$ electric-powered wheelchair, $\mathrm{HOQ}=$ house of quality, ISO = International Organization for Standardization, LED = light-emitting diode, $\mathrm{MW}=$ manual wheelchair, PAPAW = pushrim-activated power-assist wheelchair, $\mathrm{QFD}=$ quality function deployment, $\mathrm{rpm}=$ revolutions per minute.

*Address all correspondence to Tsung-Yuan Kuo, PhD; Department of Mechanical Engineering, Southern Taiwan University of Science and Technology, Tainan 710, Taiwan, R.O.C.; 886-6-2533131, ext 3000; fax: 886-6-3010069. Email: tykuo@mail.stust.edu.tw

http://dx.doi.org/10.1682/JRRD.2013.11.0250 
beneficial to the user's health when properly used. However, the gross mechanical efficiency of such wheelchairs (i.e., the ratio of the external power to the metabolic power) is just 2 to 13.8 percent, depending on the level of injury, the propulsion technique, the adjustments made to the wheelchair interface (e.g., the seat height), and the intensity of the exercise undertaken [2-9]. This low mechanical efficiency, coupled with the high physical strain imposed on the movements of the user, may result in fatigue or even strain-induced injuries in the worst-case scenario [10-12]. As a result, the design and development of electric-powered wheelchairs (EPWs) or power-assisted wheelchairs has attracted increasing attention in recent decades [13-14].

Compared with MWs, EPWs have several important advantages, including a reduced user effort and a lower risk of strain-induced injuries [1,15-22]. Consequently, EPWs have gained in popularity and importance in recent years and have prompted an increasing number of users to switch from manual propulsion to motor-powered propulsion [13]. However, present EPWs still have many disadvantages, including a long charging time, a large physical size, a heavy weight, and a high expense. Furthermore, most EPWs are inconvenient to maintain because of their many mechanical and electrical components. In addition, they cannot be easily folded or disassembled and are therefore cumbersome to store and transport [13,15-22]. Consequently, their market share is not yet as much as that of traditional MWs.

Wheelchairs that use a combination of human power and electric power have been developed recently, such as pushrim-activated power-assist wheelchairs (PAPAWs) [13-14]. The human power is delivered by the arms' action on the pushrims, while the electric power from a battery is delivered by an electric motors' torque. A typical PAPAW can sense the torque on the pushrim to generate proper assist torques by motors. The PAPAW can help its user maintain physical condition because the risk of pain and injuries to the upper limbs is greatly reduced. However, the tuning of a PAPAW may be a challenge for individual users because of the strong dependence upon the user's interaction.

The motors used to drive electric wheelchairs run on batteries. As a result, they have a relatively limited travel range and require frequent recharging. Various researchers have investigated the feasibility of overcoming these limitations by fitting the wheelchair with a solar power supply [23-26]. However, to the best of the authors' knowledge, only one published patent currently exists for a solar power-assisted electric wheelchair [23]. In their design, the solar panel is fixed rigidly to the back of the wheelchair by a metal frame and cannot be disassembled at will. Moreover, the wheelchair can only be operated in an electric mode, and thus the potential benefits of the wheelchair as an exercise device are lost. Melanson [24] and Messenger [25] have also proposed the integration of a solar panel with an EPW. However, both designs suffer many of the same disadvantages as a traditional EPW, including a large physical size, a heavy weight, and a lack of foldability. Curram et al. recently developed a solarpowered wheelchair in which the weight was reduced by modifying the main frame structure [26]. However, the wheelchair cannot be manually propelled and neither the frame nor the solar power module is foldable.

To overcome the limitations of the wheelchairs described, the present study aimed to design and develop a solar power-assisted electric wheelchair featuring a switch enabling the user to choose between manual and electric propulsion mode and a quick release mechanism for the batteries and solar panels such that the chair can be disassembled and collapsed for ease of storage and transportation.

\section{METHODS}

\section{Quality Function Deployment}

The proposed wheelchair was designed using a quality function deployment (QFD) approach. Generally speaking, QFD involves the translation of customer needs into design requirements or engineering characteristics, which are then transformed into process plans and production requirements [27-31]. The first step in the QFD approach is to confirm "who" the users and professionals are, "what" they need, and "how" these needs can best be met. In the present study, the users were elderly or disabled individuals. Having identified the customer requirements (CRs), we applied a statistical approach to the questionnaire response data in order to assign a degree of importance to each CR by means of a weighting factor with a value ranging from 5 ("very important") to 1 ("not important"). The relationships between the CRs and the design requirements (DRs) could be expressed in the form of a house of quality (HOQ) matrix such as that shown in Table 1 [32-33].

In the QFD approach, the DRs reflect the users' needs and preferences for the design product (a wheelchair in 
Table 1.

Typical house of quality matrix with 5-3-1 rating scheme.

\begin{tabular}{|c|c|c|c|c|c|}
\hline \multirow{2}{*}{$\begin{array}{c}\text { Customer } \\
\text { Requirements }\end{array}$} & \multicolumn{4}{|c|}{ Design Requirements } & \multirow{2}{*}{ Weighting } \\
\hline & 1 & 2 & 3 & 4 & \\
\hline 1 & $\triangle$ & (2) & $\triangle$ & & 3 \\
\hline 2 & (-) & O & & & 2 \\
\hline 3 & & & 0 & 0 & 4 \\
\hline 4 & & O & $\triangle$ & & 5 \\
\hline 5 & & $\triangle$ & O & ๑ & 1 \\
\hline Absolute Weighting & 13 & 37 & 23 & 17 & - \\
\hline Relative Weighting & 0.14 & 0.41 & 0.26 & 0.19 & - \\
\hline
\end{tabular}

the present case) and indicate the particular features of the design that the designers must address if customer satisfaction and market success are to be achieved. In the present study, the DRs were identified by a crossfunctional team comprising wheelchair engineers, industrial designers, therapists, and clinicians. Note that the strength weightings were assigned by the design team in accordance with the relationship between the CRs and the DRs.

Finally, absolute and relative weighting values were assigned to each DR, as shown in the lower rows of Table 1. For each DR, the absolute weighting value was computed as Equation 1:

$$
A I_{j}=\sum_{i=1}^{m} W_{i} R_{i j}, 1 \leq \mathrm{m}
$$

where $A I_{j}$ is the absolute weighting rating of $\mathrm{DR}_{j}, j=$ $1, \ldots, \mathrm{n} ; \mathrm{W}_{i}$ is the weighting value assigned to $\mathrm{CR}_{i}, i=$ $1, \ldots, \mathrm{m}$; and $\mathrm{R}_{i j}$ is the weighing value describing the strength of the relationship between $\mathrm{CR}_{i}$ and $\mathrm{DR}_{j}$ [31]. The relative weighting rating, $R I_{j}$, was then calculated as Equation 2:

$$
R I_{j}=\frac{A I_{j}}{\sum_{k=1}^{n} A I_{k}}, 1 \leq \mathrm{n}
$$

\section{Solar Power System Evaluation}

The performance of the solar power system in the proposed wheelchair was evaluated based on the statistical results obtained for a $5 \mathrm{~kW}$ solar power system given an annual average effective daily sunshine exposure of $3.44 \mathrm{~h}$ in Tainan, Taiwan [34].

\section{Travel Range}

The maximum theoretical travel range of the prototype wheelchair was computed using the energy consumed over the experimental tract accompanied by the measurement of the depletion of a fully charged battery with a known capacity as exhibited by Equation 3:

$$
R=\frac{C \times D}{E \times 1000}
$$

where $R$ is the theoretical maximum driving range (in kilometers) given a full battery capacity, $C$ is the battery capacity (in ampere-hours), $D$ is the distance of the testing track (in meters) $\times 20$, and $E$ is the amount of current consumed during the test (in ampere-hours).

The performance of the prototype wheelchair was evaluated both with and without the solar panel module attached to the power supply system. In order to ensure the reliability of the test results, the test was done by a nondisabled subject. The test procedure was conducted between the hours of $10 \mathrm{a} . \mathrm{m}$. and 12 p.m., with an average measured sunlight intensity of $850 \mathrm{~W} / \mathrm{m}^{2}$.

\section{Static Stability Test}

The static stability of the wheelchair was tested in accordance with the International Organization for Standardization (ISO) 7176-1 standard [35]. Specifically, the wheelchair was secured on a platform using restraining straps positioned in such a way as to avoid interfering with the tipping movement. A $100 \mathrm{~kg}$ dummy was placed in the wheelchair and the angle of the platform was then slowly adjusted until the angle was found at which the chair tipped. The stability of the occupied wheelchair was characterized by three variables: (1) the forward tip-over angle, (2) the rearward tip-over angle, and (3) the lateral tip-over angle.

\section{RESULTS}

\section{Quality Function Deployment Analysis Results}

The CRs for the wheelchair were determined by means of a questionnaire distributed to 40 users ( 24 male, 16 female, average age $31.5 \pm 10.5 \mathrm{yr}$, average weight $68.3 \pm 11.1 \mathrm{~kg}$, average height $167.5 \pm 7.2 \mathrm{~cm}$, all using a wheelchair as their primary means of mobility within the community). The HOQ matrix for the solar powerassisted manual/electric wheelchair is shown in Table 2. 
The CRs comprise a total of 13 subitems and are divided into three main groups: functional requirements, ergonomic requirements, and interface requirements. Note that the weighting (i.e., degree of importance) of each CR is shown in the right-most column of Table 2. The DRs are grouped into four categories, dimensions, safety, part characteristics, and others, and include such items as the weight, operation functions, collapsing steps, travel range, and assembling time. The relationships between the CRs and DRs are moderated using weighing factors with values of 1,3 , or 5 , representing a "weak relationship," a "medium relationship," and a "strong relationship," respectively.

Generally speaking, a larger value of $R_{I j}$ indicates that the corresponding DR is a more critical design requirement. Thus, in the present study, "operation functions," "travel range," and "assembling time" were identified as critical DRs. In completing the QFD design process, a design goal (target) was assigned to each DR (critical or otherwise) by the design team in accordance with the QFD analysis and the findings of previous studies.

\section{Conceptual Design}

Figure 1 presents a schematic illustration of the prototype manual/electric wheelchair developed in the present study. For ease of assembly and retraction, the wheelchair is based on the frame of a commercially available, manually propelled chair (KM-8520, KangYang Hardware Enterprise Co Ltd; New Taipei City, Taiwan). Moreover, an electric propulsion capability is achieved by means of a battery set (the main power source) and two electric motors (one motor per driven wheel). The travel range of the wheelchair is extended via the use of a solar panel auxiliary power supply. As shown in Figure 1, the solar panel is installed in such a way as to provide a roof over the user's head, thereby acting not only as a secondary power source but also as a shelter against the sun and rain. Importantly, the

Table 2.

House of quality correlation matrix for solar power-assisted manual/electric wheelchair.

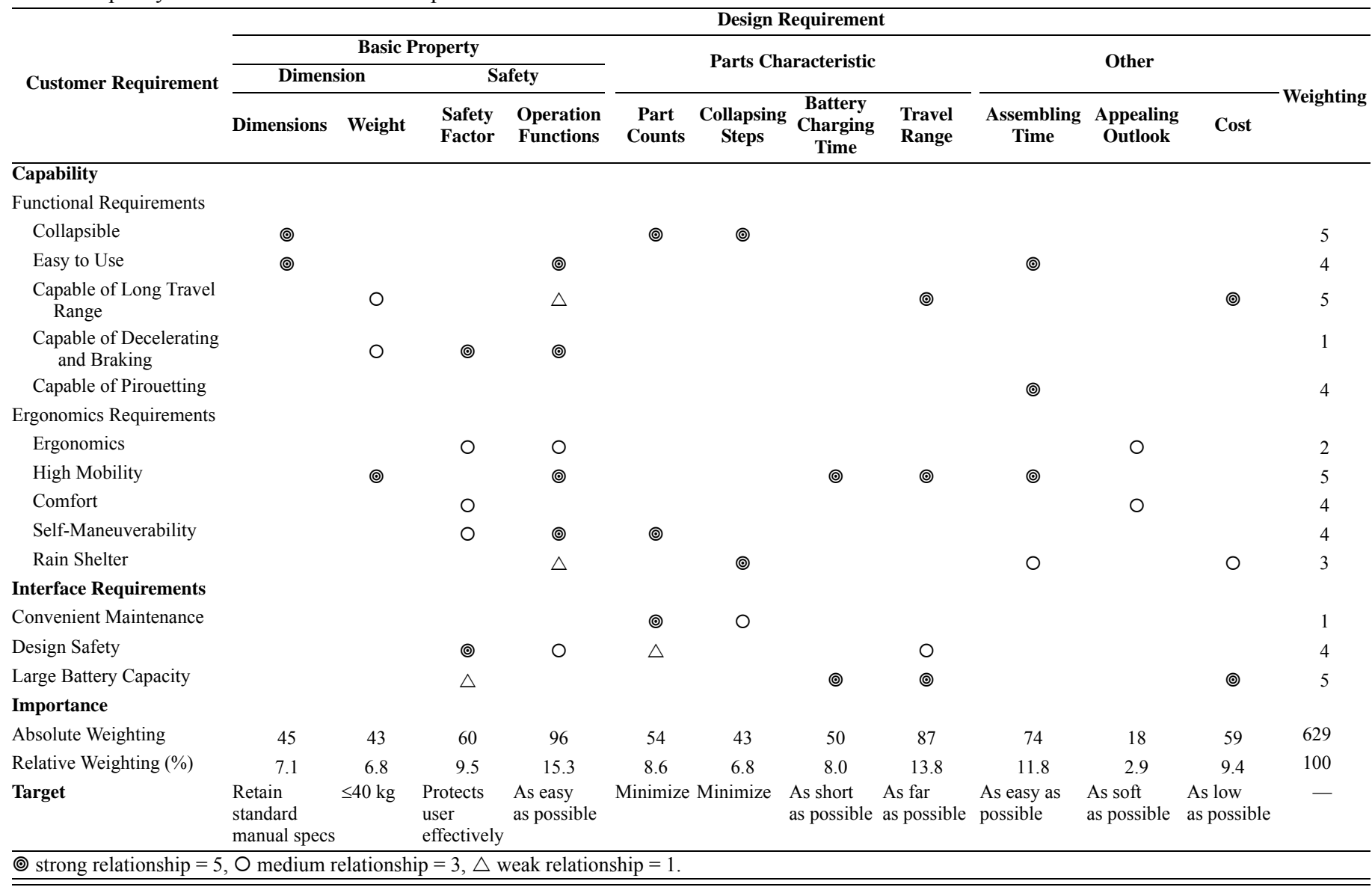




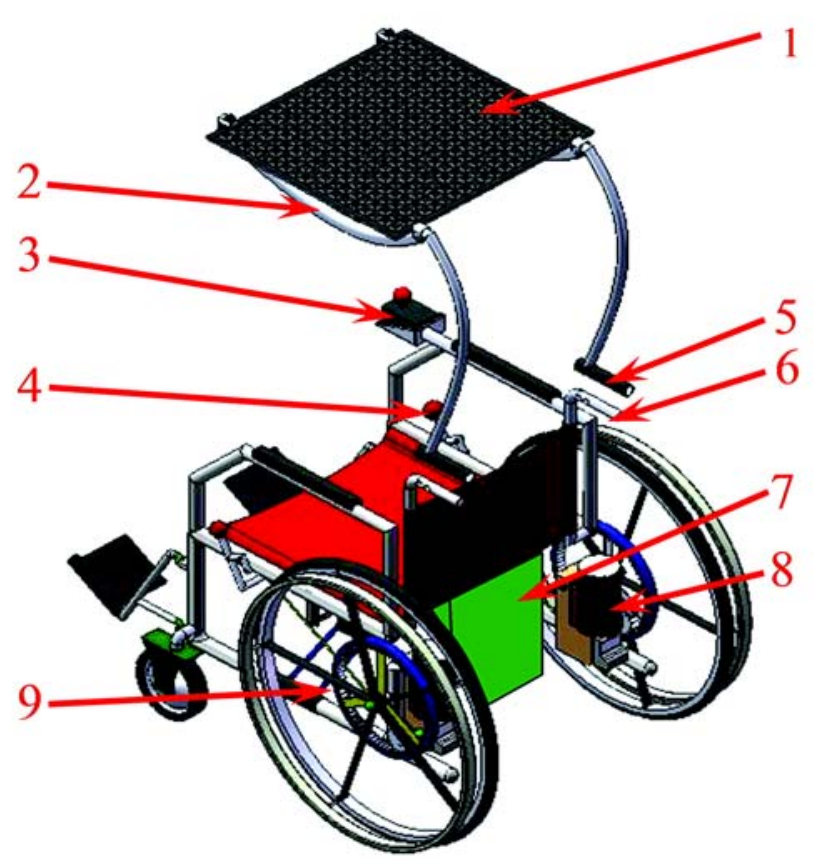

Figure 1.

Conceptual design of solar power-assisted manual/electric wheelchair proposed in present study. (1) Solar panel (single crystal, $60 \mathrm{~W}$ ), (2) foldable frame for solar panel, (3) steering joystick and controller, (4) manual/electric mode switch, (5) quick release for solar panel's frame, (6) wheelchair handle, (7) batteries, (8) motor $(50 \mathrm{~W} \times 2)$, (9) planetary gear.

wheelchair is fitted with a manually operated clutch mechanism enabling the user to change at will between a manual propulsion mode and an electric propulsion mode. Finally, the solar panel assembly is based on a modular design and is equipped with "quick release" mechanisms in order to enable the chair to be collapsed and folded for storage and transportation purposes.

Figure 2 presents the electric circuit of the proposed wheelchair. As shown, the battery and solar panel are connected in parallel, with a diode placed between them in order to prevent a reverse flow from the battery to the solar cells. In the electric propulsion mode, the battery (or solar cell) supplies power to a control unit, which issues commands to drive the motors of the two wheels in accordance with the direction and velocity inputs provided by the user through a hand-activated joystick.

\section{Prototype Wheelchair}

Figure 3 presents a photograph of the prototype wheelchair. The basic specification details of the wheelchair are provided in Table 3. As stated previously, the wheelchair is based on the frame of a commercially available manual wheelchair and has a weight of $17.4 \mathrm{~kg}$. The auxiliary components of the wheelchair, e.g., the solar panels, battery set, and planetary gears, have a combined weight of $21.6 \mathrm{~kg}$. Thus, the wheelchair has a total weight of approximately $39 \mathrm{~kg}$. Figure 4 illustrates the planetary gear set used in the proposed wheelchair as a deceleration mechanism and a switching component between the manual driving mode and the electric driving mode. The major modules of the proposed wheelchair are briefly described in the following sections.

\section{Motors}

In general, EPWs should carry the user at a speed no greater than the prescribed speed limit $\left(6-12 \mathrm{kmh}^{-1}\right.$ in most countries) and should be capable of carrying an individual with a weight of $90 \mathrm{~kg}$ not only on flat ground but also on $7^{\circ}$ (corresponding to a slope gradient of 1:8) uphill ramps. Note that the Americans with Disabilities Act recommends a 1:12 slope, which is around $4.8^{\circ}$ [36]. Most direct current (DC) motors rotate at hundreds to thousands of revolutions per minute (rpm) and are therefore unsuitable for driving the standard $24 \mathrm{in}$. diameter wheels of a wheelchair directly. Furthermore, while gear motors have a built-in reduction gear set, the reduction ratio is insufficient to meet the low speed requirements of a wheelchair. Thus, the prototype wheelchair developed in the present study was fitted with a planetary gear set in order to reduce the speed of the chair and increase the torque supplied to the wheels. The electric propulsion mode was provided by two 3MEN BL5S brushless DC gear motors driven by $3 \mathrm{MEN}$ BL300-0 brushless DC drivers (3MEN Technologies; New Taipei City, Taiwan). The rated speed and torque of the chosen gear motors were $2,700 \mathrm{rpm}$ and $0.19 \mathrm{Nm}^{-1}$, respectively. Meanwhile, the reduction ratio of the planetary gear set was specified as 5.31 (gear ratio $=85 / 16$ ) in order to limit the speed of the wheelchair to a range of 3 to $7 \mathrm{kmh}^{-1}$ (i.e., $2 \pi \times 12 \times$ $0.0254 \times 2,700 \times 60 / 1000 / 5.31 \approx 7.6 \mathrm{kmh}^{-1}$ ). The planetary gear set provides an improved uphill-climbing capability and a better downhill-braking capability when the wheelchair is operated in the electric mode. (Note that the 


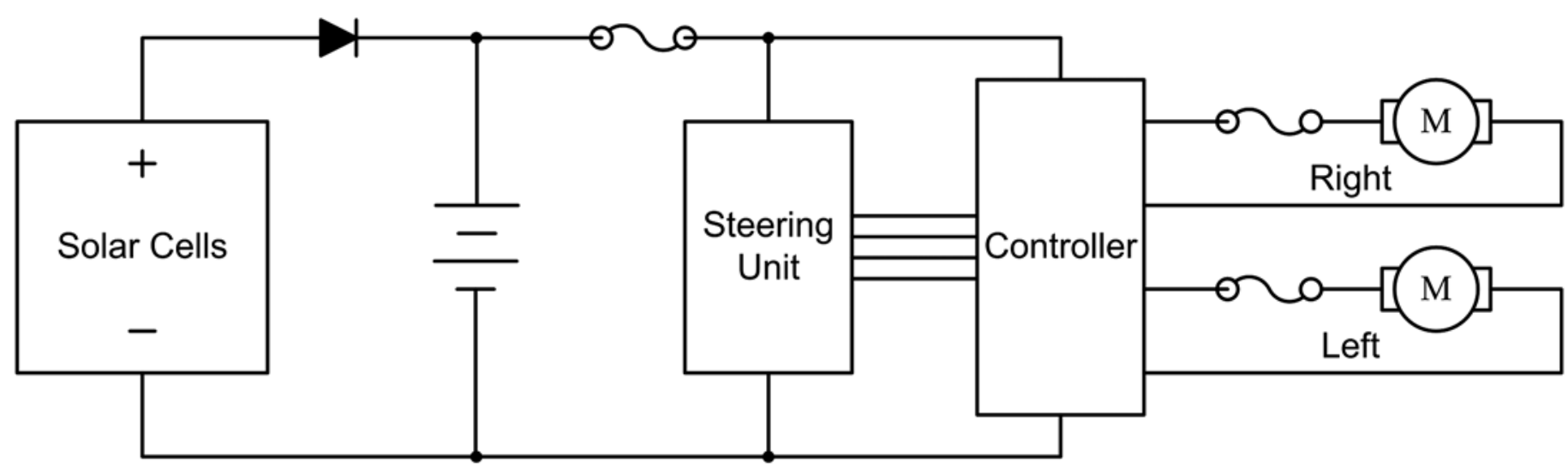

Figure 2.

Electric circuit of prototype of solar power-assisted manual/electric wheelchair. $\mathrm{M}=$ motor.

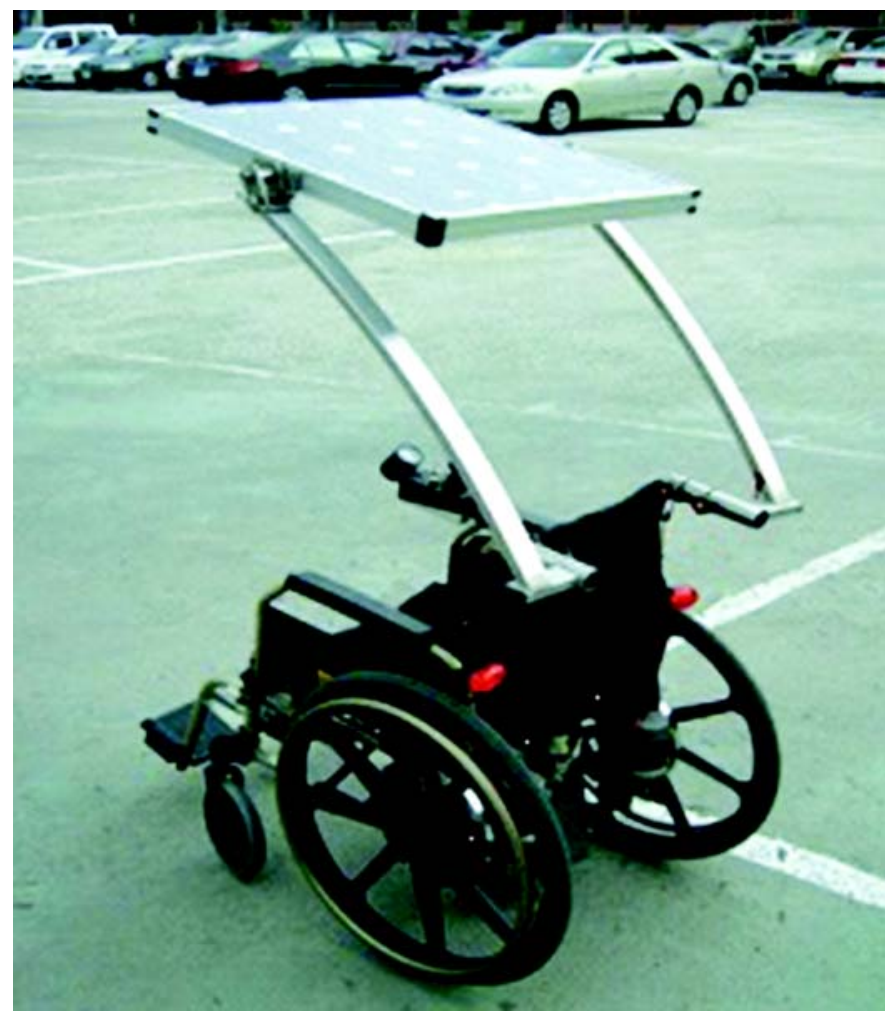

Figure 3.

Photograph of prototype of solar power-assisted manual/electric wheelchair.

climbing and braking capabilities are made possible through the interaction between the motor and the gears.)
Table 3.

Detailed specification of solar power-assisted manual/electric wheelchair.

\begin{tabular}{ll}
\hline \multicolumn{1}{c}{ Item } & \multicolumn{1}{c}{ Parameter } \\
\hline Contour Dimension & $1050 \times 610 \times 870 \mathrm{~mm}$ \\
Minimum Turning Radius & $650 \mathrm{~mm}$ \\
Addition Extra Weight & $21.6 \mathrm{~kg}$ \\
$\quad$ Solar Panels & $8 \mathrm{~kg}$ \\
Driving Hardware & $13.6 \mathrm{~kg}$ \\
Manual Wheelchair Weight & $17.4 \mathrm{~kg}$ \\
Net Weight & $39 \mathrm{~kg}$ \\
Maximum Load & $130 \mathrm{~kg}$ \\
Front Wheel Specifications $(\times 2)$ & $8 \mathrm{in}$. \\
Rear Wheel Specifications $(\times 2)$ & $24 \mathrm{in}$. \\
Motor Voltage & $24 \mathrm{~V}(\mathrm{DC})$ \\
Motor Power $(\times 2)$ & $100 \mathrm{~W}$ \\
Battery $(\times 2)$ & Lead-acid battery \\
Chargers Input & $12 \mathrm{~V} / 12 \mathrm{Ah}$, AC $110 \mathrm{~V} / \mathrm{AC}$ \\
& $220 \mathrm{~V}$ \\
\hline AC $=$ alternating current, DV = direct current. \\
\hline
\end{tabular}

\section{Power Sources}

The main power supply for the wheelchair was provided by two $12 \mathrm{~V}_{\text {DC }}$ (12Ah) YUASA (YTX14-BS, Taiwan Yuasa Battery Company; New Taipei City, Taiwan) rechargeable lead-acid batteries connected in series. In addition, the wheelchair was fitted with a solar panel as an auxiliary power supply. When the wheelchair is operated in the electric mode, the driving power is provided by both the batteries and the solar power supply, with the contribution of the solar panel being determined by the sunlight intensity and the residual battery voltage. Moreover, when operated in the manual mode or stopped 


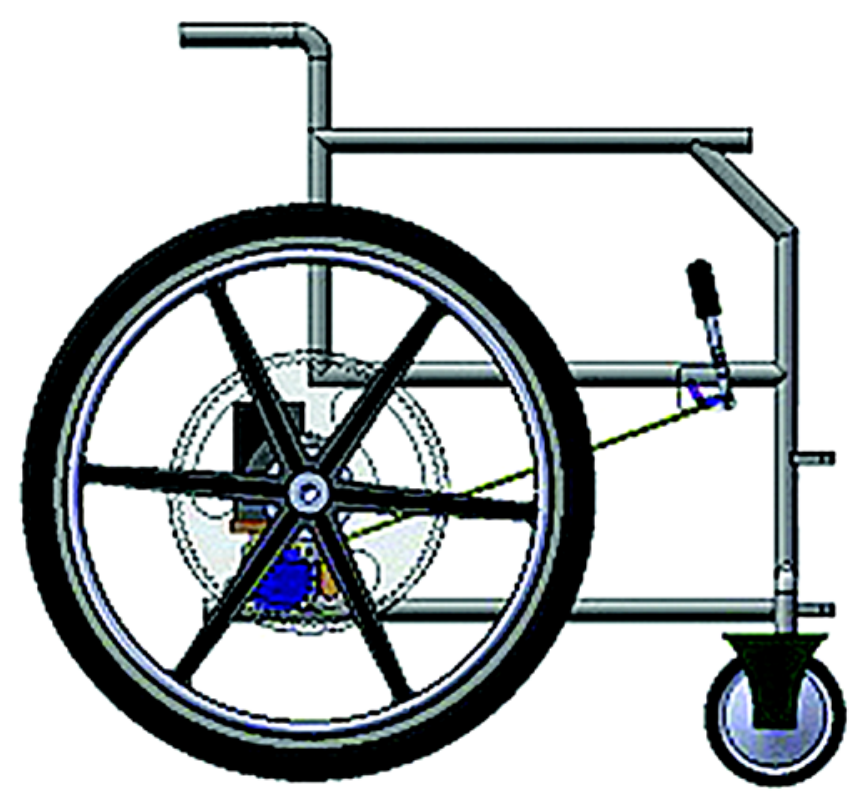

Figure 4.

Schematic illustration of manual/electric mode switch mechanism.

under the sun, the solar power system charges the battery set for later use. The simulated $I-V$ (current vs voltage) $P-V$ (power vs voltage) characteristics of each of the solar cells in the solar panel are shown in Figure 5. The maximum current that the solar panel can provide is around $2.45 \mathrm{~A}(60 \mathrm{~W} / 24.5 \mathrm{~V} \approx 2.45 \mathrm{~A})$.

\section{Solar Panel Module}

As described previously, the battery set used as the main power supply for the wheelchair has a total output voltage of $24 \mathrm{~V}_{\mathrm{DC}}$. Accordingly, in selecting the auxiliary power supply, a solar panel module with a power of $60 \mathrm{~W}$ and a nominal voltage of $24.5 \mathrm{~V}$ was chosen. The solar panel had dimensions of $540 \times 620 \mathrm{~mm}$ and a conversion efficiency of the single crystalline silicon solar panel module is 15 percent. The $I-V$ and $P-V$ curves (Figure 5) show that the maximum efficiency of the solar panel is obtained at an output voltage of around $7 \mathrm{~V}$. Furthermore, the test results indicated that the $60 \mathrm{~W}$ solar power module was capable of generating 206.4 Wh every day, equal to $13.76 \mathrm{Ah}$ for a $12 \mathrm{~V}$ battery with an efficiency of around 80 percent.

In order to improve the solar power conversion efficiency, the solar panel was mounted on the wheelchair using an angular adjustment mechanism comprising a location pin, a spring, and a series of positioning holes (Figure 6).

\section{Manual/Electric Mode Switch}

In the proposed wheelchair, a power drive module and mechanical clutch mechanism are used to facilitate both a manual driving mode and an electric driving mode. The change between the two driving modes is made by using a switch rod to engage the driven gear with the driving gear (electric mode) or disengage the
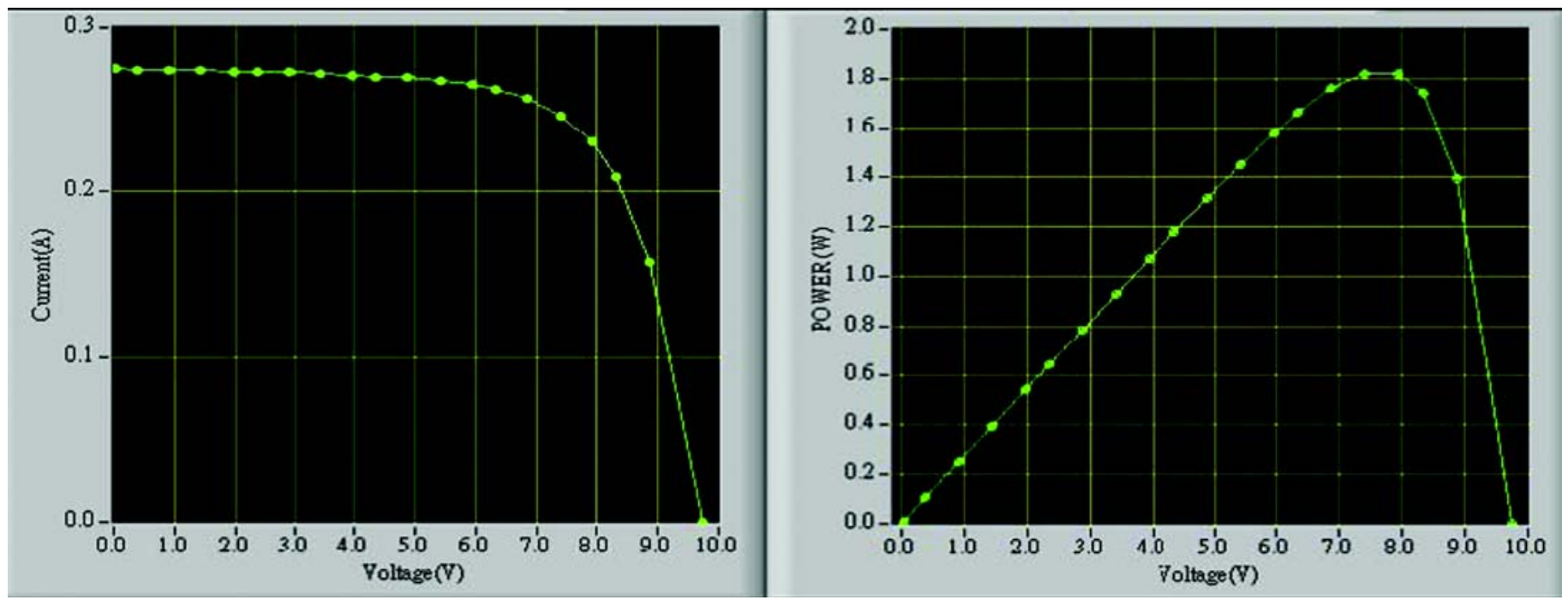

Figure 5.

Simulated characteristic curves of solar cell. 
(a)

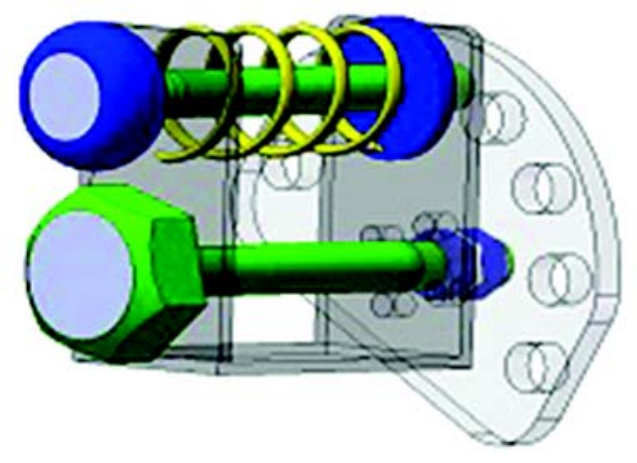

(b)

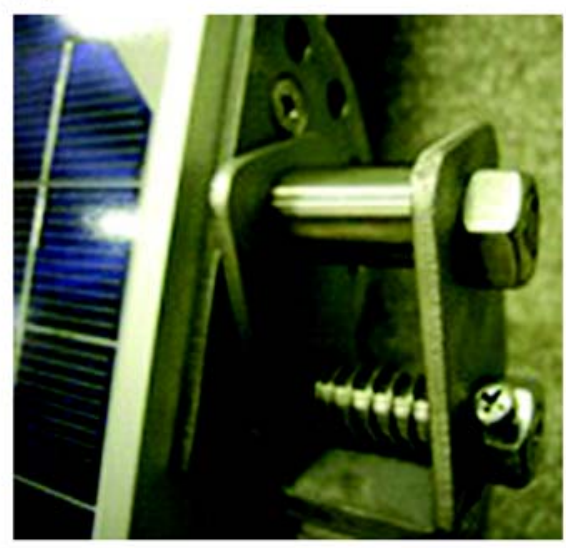

(c)

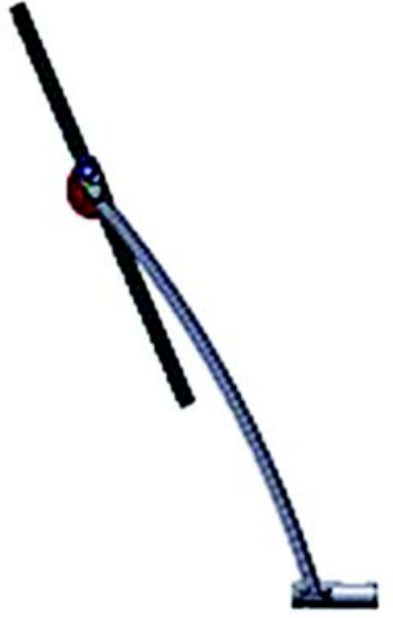

Figure 6.

Angle adjustment component of solar panel module: (a) schematic illustration, (b) photograph, and (c) folded solar panel.

driven gear from the driving gear (manual mode). (Note that the mechanism design has been patented [37].) Figure 7 shows the detailed components of the switch mechanism. Changing between the two driving modes requires the application of a force of just $20 \mathrm{~N}$ to the handle attached to the switching rod (Figure 4).

\section{Steering Joystick and Controller}

The steering module comprises a hand-activated joystick and a controller (within a box) mounted on the armrest of the wheelchair, as shown in Figure 8. Through the use of the joystick, the wheelchair can be controlled to move in a straight line in the forward or reverse direction, to turn left, or to turn right. The proposed wheelchair uses two motors to power the drive wheels and has a differential steering capability similar to that of EPWs. As a result, the wheelchair is capable of pirouetting.

\section{Battery Monitor and LED Taillights}

In general, the life of rechargeable batteries is shortened by excessive discharging and overcharging. However, by force of habit, most users charge their wheelchairs every night such that the batteries are fully charged in the morning. Nonetheless, a voltmeter was positioned in front of the hand-activated joystick in order to provide an indication as to the amount of battery life remaining (Figure 8). In addition, two light-emitting diodes (LEDs) were mounted on the rear of the seat to act as taillights (Figure 3).

\section{Quick Release Mechanisms}

The prototype wheelchair was built around the main frame of a commercial foldable MW. The various components and modules of the wheelchair were attached to the main frame by means of quick-release fasteners, thereby enabling the chair to be disassembled and collapsed for ease of storage or transport (Figure 9). Both the solar panel and the battery set must be removed from the frame before the chair can be collapsed and folded. Thus, compared with traditional MWs, the disassembly process takes longer and requires the assistance of a nondisabled individual. However, compared with most EPWs, which require a van or specially designed vehicle to transport the wheelchair, the convenience offered by the proposed chair in being able to be transported in a regular car is regarded as a major advantage.

\section{Tests}

\section{Travel Range}

The maximum travel range of the wheelchair was tested with and without the solar power module attached to the power supply system. The wheelchair was fitted with a lead-acid battery set of $24 \mathrm{~V} / 12 \mathrm{Ah}$, and the combined weight of the user and the wheelchair was $114 \mathrm{~kg}$ (wheelchair: $39 \mathrm{~kg}$, user: $75 \mathrm{~kg}$ ). In the test procedure, the user was asked to complete 20 laps of a $100 \mathrm{~m}$ track at an average speed of $2 \mathrm{kmh}^{-1}$. Note that this speed was 

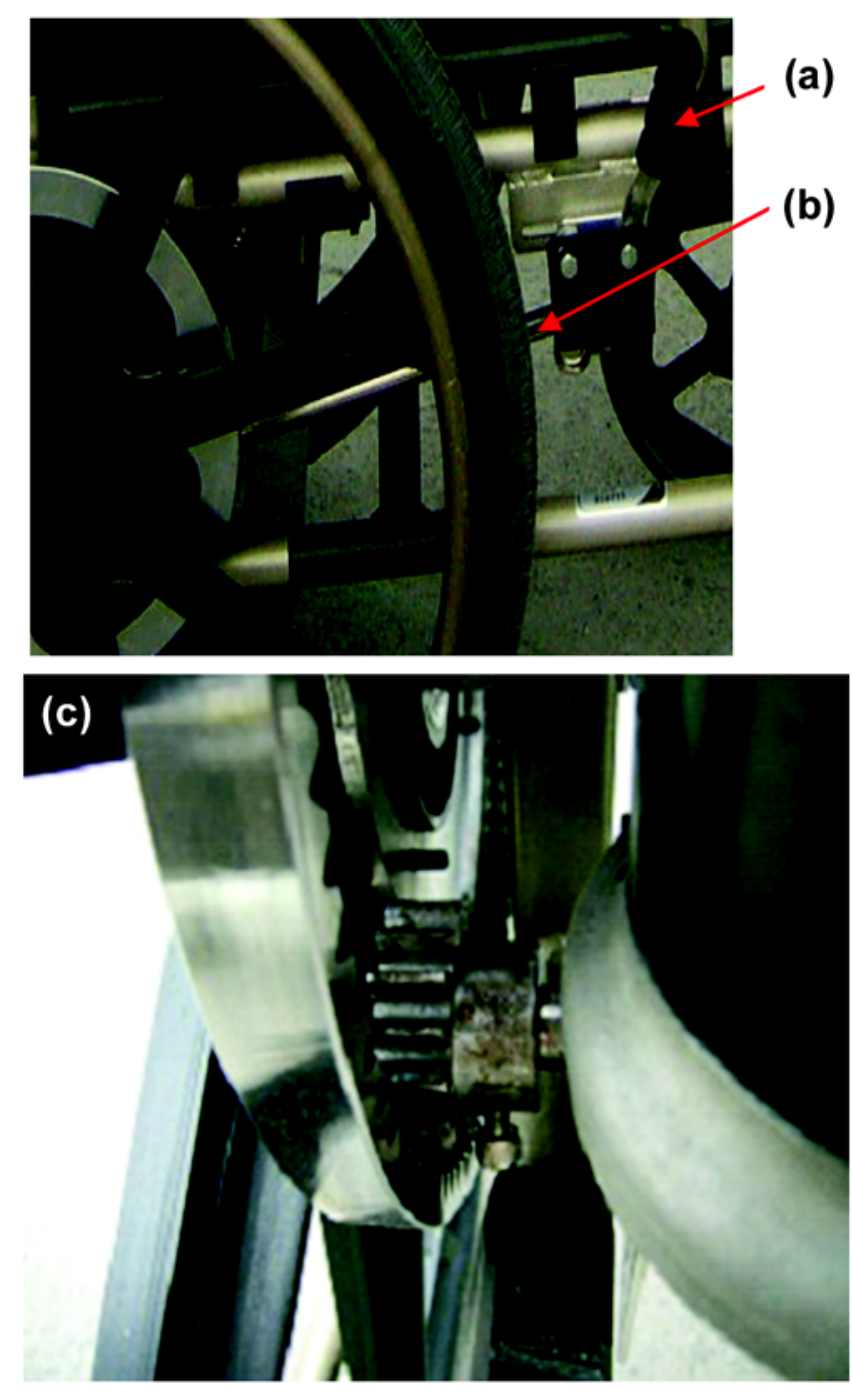

Figure 7.

Photographs of manual/electric mode switch mechanism: (a) switching rod, (b) connecting linkage, and (c) planetary gears.

specified in accordance with the average travel speed of an individual driving a conventional EPW [38]. The test results showed that the current consumption was $1.42 \mathrm{Ah}$ using the solar power supply and 1.79 Ah using the battery set alone. The travel range was computed using an 80 percent battery capacity as the benchmark. Thus, from Equation 3, the maximum theoretical travel range was calculated to be $13.52 \mathrm{~km}$ and $10.72 \mathrm{~km}$ with and without the solar power supply, respectively. In other words, the solar panel increased the maximum travel range of the wheelchair by approximately 26 percent (i.e., $(13.52-10.72) / 10.72 \times 100 \%=26 \%$ ).
Table 4.

Static tip-over angles (in degrees) of proposed wheelchair, EPWs and MWs [39-40].

\begin{tabular}{lccc}
\hline \multicolumn{1}{c}{ Wheelchair } & Forward & Rearward & Lateral \\
Proposed Wheelchair & 23 & 20 & 20 \\
EPW & & & \\
E\&J Lanser & 28 & 20 & 18 \\
Quickie P200 & 22 & 23 & 19 \\
Invacare Storm & 20 & 24 & 16 \\
Pride Jazzy & 21 & 15 & 16 \\
Permobil Chairman & 30 & 18 & 20 \\
Mean Value & 24.2 & 20 & 17.8 \\
MW & & & \\
TiLite AeroZ & 23 & 29 & 21 \\
Invacare Grossfire & 24 & 10 & 24 \\
Quickie GT & 21 & 26 & 18 \\
Kuschall AirPro & 24 & 8 & 19 \\
Mean Value & 23 & 18.3 & 20.5 \\
\hline EPW = electric-powered wheelchair, MW = manual wheelchair. & \\
\hline \hline
\end{tabular}

\section{Static Stability}

Figure 10 presents two photographs of the static stability test configuration. The results of the stability tests are shown in Table 4. All three angles significantly exceed the value of $7^{\circ}$ specified by the ISO 7176-1 standard [35]. Thus, the static stability of the proposed wheelchair is confirmed. The tipping angle of several mainstream EPWs and MWs [39-40] are also shown in Table 4. It is clear that the static stability varies with different wheelchairs. Compared with the EPWs and MWs, the tip-over angles of the proposed wheelchair in the forward and rearward orientation are the middle values in the corresponding columns, while the angle is larger than the middle value in the lateral orientation. In the stability test, the larger the tip-over angle is, the more stable the wheelchair is. Thus, it can be concluded that the static stability of the proposed wheelchair is either average or better than the average.

\section{DISCUSSION}

\section{Travel Range}

The travel range of an EPW is determined by many different factors, including the battery type and size, the battery state, the combined wheelchair/user weight, the terrain, the efficiency of the drive train, and the driving behavior of the user [41]. In the case of the prototype 


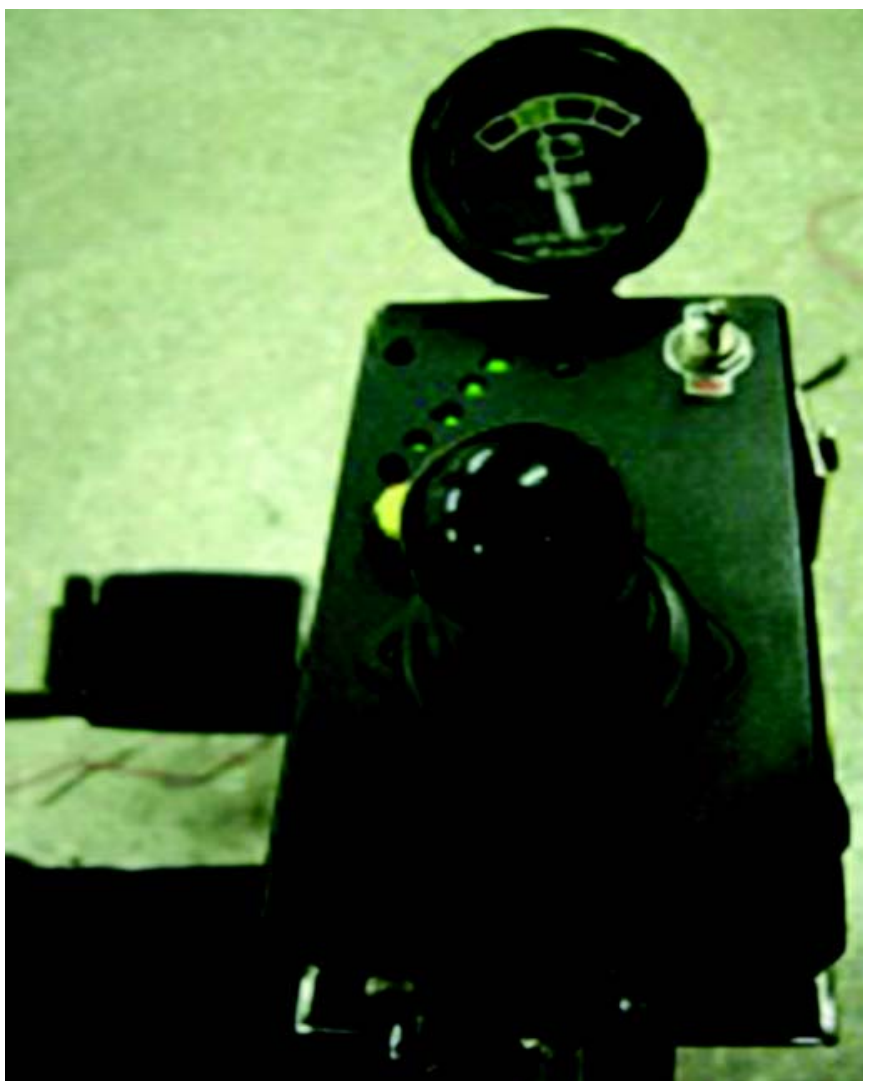

Figure 8.

Steering joystick and controller.

wheelchair proposed in this study, the travel range is further affected by such factors as the solar cell efficiency, the sunlight intensity, and the travel speed. The test results showed that the use of the solar power system resulted in a 26 percent improvement in the travel range. However, the battery used in the present tests had a capacity of just $12 \mathrm{Ah}$, i.e., around 3 to 6 times lower than that of a commercial EPW battery [42]. Thus, it is reasonable to assume that if the battery in the prototype wheelchair is replaced with a commercial EPW-grade battery, a more significant improvement in the travel range can be obtained.

The prototype wheelchair was fitted with a conventional lead-acid battery set in order to evaluate the basic feasibility of the hybrid battery-solar panel power supply. However, as battery chemistry improves, we anticipate that the lead-acid battery set can be replaced with a lowmaintenance, high-energy-density lithium-ion or lithiumion polymer battery set.

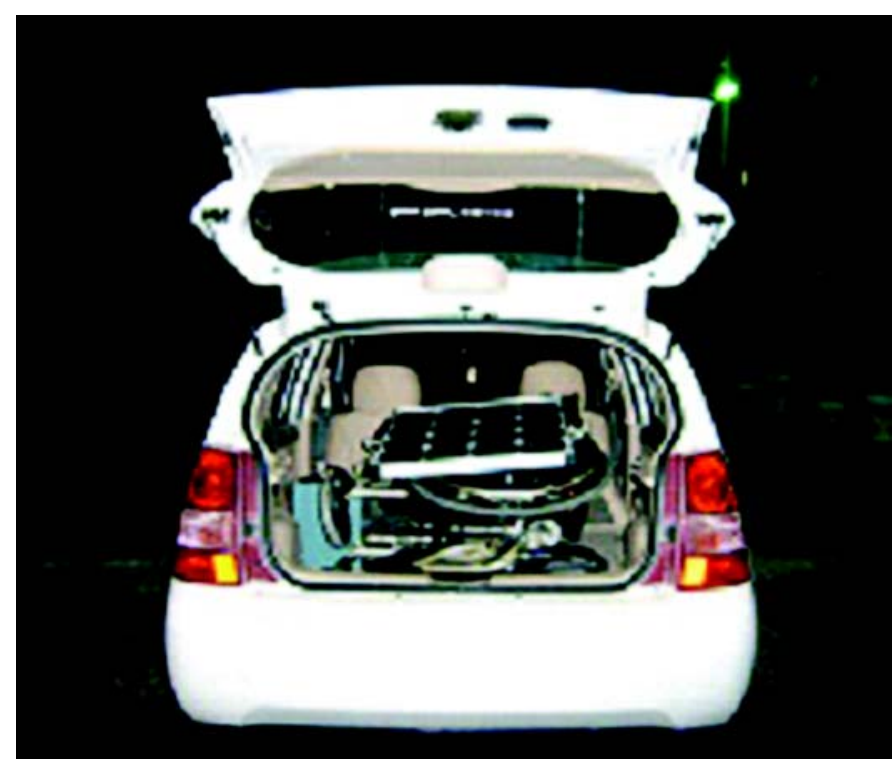

Figure 9.

Photograph of folded prototype wheelchair in car trunk.

\section{Static Stability}

The forward, rearward, and lateral tip-over angles of the wheelchair depend on the relationship between the position of the overall center of gravity (CG) of the chair and its base of support. Specifically, tip over occurs under either static or constant velocity conditions when the vertical projection of the combined CG of the wheelchair exceeds a certain angle [43]. In practice, the stability of the wheelchair can be improved by lowering the CG [44-46]. Thus, in the prototype wheelchair, all of the major components other than the solar panels were positioned beneath the seat in such a way as to lower the CG and move its position to the approximate center point of the chair.

\section{Effects of Additional Mass}

A previous study reported that the placement of an additional 5 to $10 \mathrm{~kg}$ at the rear wheel or under the seat of a manual wheelchair has only a minimal effect on the power output, physical strain, and propulsion time [4750]. Consequently, the wheeling velocity, percentage push time [48], energy expenditure, heart rate, and sprint time [49] showed no significant change. However, another study showed that an additional mass of $9.05 \mathrm{~kg}$ resulted in a lower velocity and greater resultant and tangential forces [50]. The difference in the findings regarding the effects of the additional mass is most likely the 


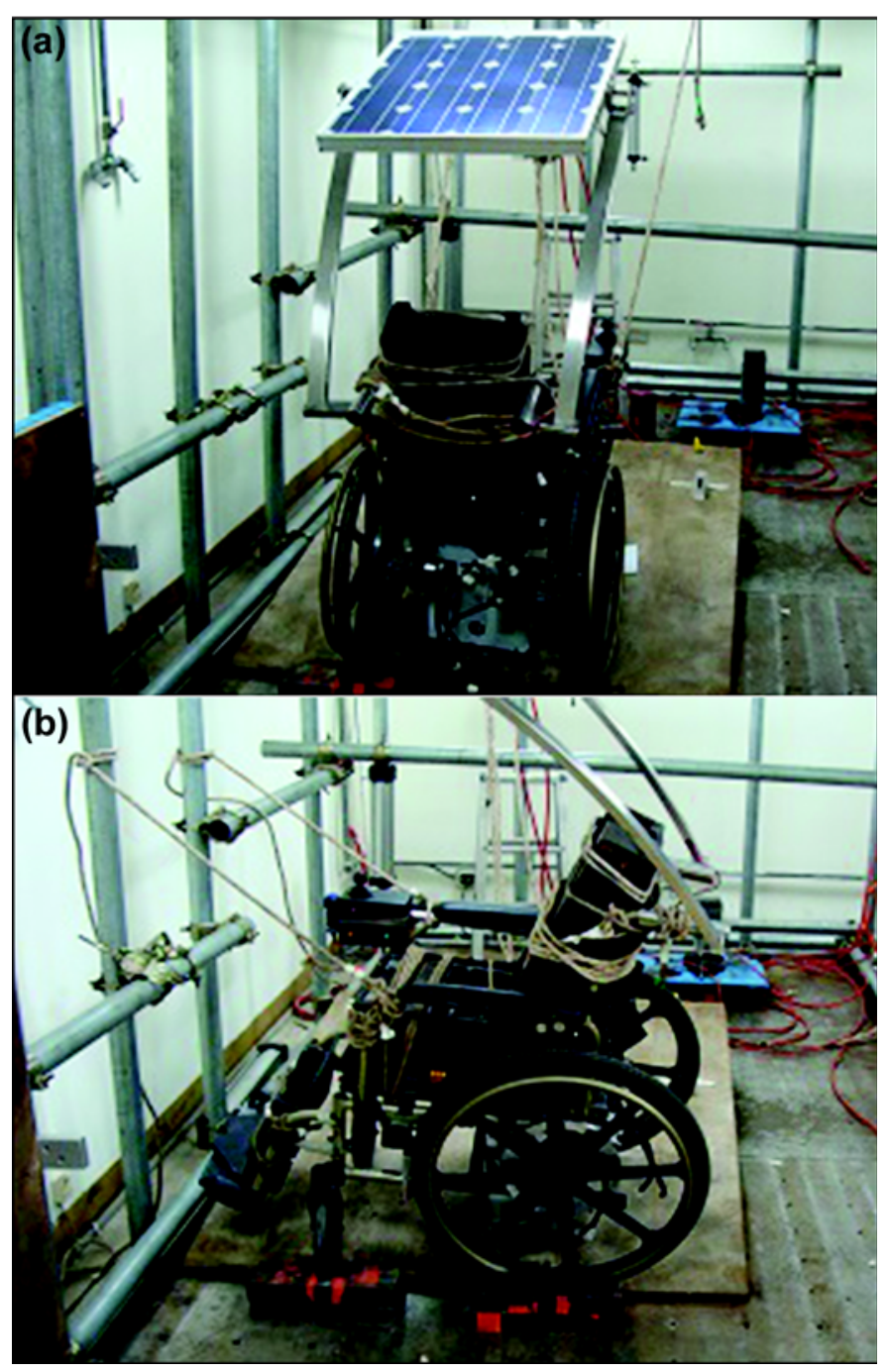

Figure 10.

Static stability evaluation of solar power-assisted manual/electric wheelchair: (a) rearward, and (b) lateral. Note that all tests were conducted using least stable configuration.

result of differences in the position in which the mass is placed [47-50]. In the present study, the electric propulsive components placed beneath the seat have a weight of $13.6 \mathrm{~kg}$, while the solar panel modules placed above the user's head have a mass of $8 \mathrm{~kg}$. Since the bulk of the additional mass is placed beneath the seat, the wheelchair maintains good stability. However, the effects of the additional mass (both beneath the seat and over the user's head) on the manual performance of the wheelchair require further investigation in a future study.

The prototype wheelchair developed in this study is intended for users who have the ability to operate a MW.
However, in contrast to a conventional MW, the proposed chair is fitted with a mechanism enabling the user to switch at will between a manual propulsion mode and an electric mode. Consequently, the chair both helps the user achieve a strengthening of the cardiopulmonary functions and reduces the possibility of shoulder injuries as a result of the long-term use of the manual propulsion mode. The additional mass of $21.6 \mathrm{~kg}$ contributed by the electric propulsive equipment and solar power components to the overall weight of the wheelchair may increase the risk of shoulder injury. Thus, the electric driving mode plays an essential role in minimizing the risk of injuries. In the present stage of development, the auxiliary components in the proposed wheelchair are fabricated of mild steel and stainless steel. As a result, they are all relatively heavy. Studies have shown that Al 6061-T6 alloy has a high yield strength (35-40 ksi) and a density equal to just 66 percent of that of A36 mild steel. ${ }^{*}$ Moreover, it has been shown that the use of $\mathrm{Al}$ 6061-T6 alloy to construct the frame of a manual wheelchair results in a weight saving of around $10 \mathrm{~kg}$ with no loss in strength or mechanical integrity [39]. Thus, in a future study, aluminum alloy will be used to replace all of the mild steel components of the proposed solar power-assisted wheelchair.

\section{Functions of Proposed Solar Power-Assisted Manual/ Electric Wheelchair}

In the manual mode, the proposed wheelchair is intended to strengthen the cardiopulmonary function and upper-limb muscular strength of the user. By contrast, in the electric mode, the wheelchair is intended to increase the user convenience and minimize the risk of straininduced injuries. The main advantages and features of the proposed wheelchair can be summarized as follows:

1. The wheelchair can be easily switched from a manual mode to an electric mode by means of a simple leveractuated mechanical clutch.

2. The steering/control system is simple to operate and enables both the speed and direction of the wheelchair to be precisely controlled. For user safety, the wheelchair is fitted with both a horn and LED back lights. In addition, for user convenience, a voltmeter is mounted

\footnotetext{
*Aluminum \& mild steel load question [Internet]. Physics Forums; 2010. Available from: https://www.physicsforums.com/threads/aluminum-mild-steel-load-question-new-member.400543/
} 
next to the joystick in order to provide an indication as to the amount of battery life remaining.

3. The planetary gear set provides an improved uphillclimbing capability and a better downhill-braking capability when the wheelchair is operated in the electric mode.

4. The prototype wheelchair can be disassembled and folded for ease of storage or transport.

\section{Limitations}

In general, the aim of the present study was simply to demonstrate the feasibility of the proposed wheelchair design and to conduct a preliminary investigation into the effect of the solar power module on the travel range of the chair. At present, our laboratory lacks the equipment required to perform a full investigation into the performance of the wheelchair and its various components, and thus further in-depth testing is required before commercialization can be considered. The limitations of the present study (and thus the implications for future work) can be summarized as follows:

1. Although the static stability of the prototype wheelchair has been demonstrated, further testing is required to investigate its dynamic stability and durability in accordance with relevant international standards (e.g., ISO, American National Standards Institute/Rehabilitation Engineering and Assistive Technology).

2. A detailed investigation should be performed into the effects of the installed components (e.g., solar panels, electric propulsive components) on all aspects of the wheelchair performance, including its dynamic stability, power output, and mechanical integrity.

3. A detailed assessment should be conducted of the effect of the additional weight of the installed equipment on the performance of the wheelchair in the manual mode and the potential risk of shoulder injury. Furthermore, the feasibility and effects of fabricating the main frame of the chair and its auxiliary components from lightweight aluminum alloy should be carefully examined.

4. For safety considerations, the current wheelchair design requires the assistance of a nondisabled individual to disassemble and collapse the wheelchair and place it in a vehicle.

5. The main aim in developing the manual/electric propulsion mode in the present wheelchair was to enable the user to switch freely between the two modes in order to minimize the risk of shoulder injury (electric mode) and to improve the user's cardiopulmonary function and upper-limb muscle strength (manual mode). Since the chair can be manually propelled, its full benefits can only be acquired by users who actually have the ability to propel the chair in this mode. In other words, the wheelchair has only limited benefits for those with weak or impaired arms.

\section{CONCLUSIONS}

This study used a QFD approach to design and develop a solar power-assisted manual/electric wheelchair. The principal features of the proposed wheelchair are as follows: (1) a solar panel to serve as an auxiliary power supply, thereby increasing the travel range; (2) a mechanical clutch mechanism to enable the user to switch at will between a manual operation mode and an electric operation mode; (3) a dedicated DC motor for each wheel to improve the wheelchair maneuverability; (4) a planetary gear system to improve the uphill-climbing ability and downhill-braking capability when in the electric mode; and (5) a modular construction design to enable the rapid disassembly and retraction of the wheelchair for ease of storage and transportation.

\section{ACKNOWLEDGMENTS}

\section{Author Contributions:}

Study concept and design: T. Liao, T. Kuo. Acquisition of data: C. Chien, T. Lee, T. Liao, T. Kuo. Analysis and interpretation of data: T. Huang, T. Kuo. Drafting of manuscript: T. Liao.

Critical revision of manuscript for important intellectual content: T. Huang, T. Kuo.

Statistical analysis: C. Chien, T. Lee, T. Liao.

Obtained funding: C. Chien, T. Lee, T. Kuo.

Administrative, technical, or material support: C. Chien, T. Lee, T. Kuo.

Study supervision: T. Kuo.

Financial Disclosures: The authors have declared that no competing interests exits.

Additional Contributions: Tze-Yuan Liao is now with Quintain Steel Company.

Funding/Support: This material was based on work supported by Southern Taiwan University of Science and Technology, Republic of China (Taiwan). 


\section{REFERENCES}

1. Yang YP, Huang WC, Lai CW. Optimal design of rim motor for electric powered wheelchair. IET Electric Power Appl. 2007;1(5):825-32. http://dx.doi.org/10.1049/iet-epa:20060470

2. Leary M, Gruijters J, Mazur M, Subic A, Burton M, Fuss FK. A fundamental model of quasi-static wheelchair biomechanics. Med Eng Phys. 2012;34(9):1278-86.

[PMID:22763021]

http://dx.doi.org/10.1016/j.medengphy.2011.12.018

3. de Groot S, de Bruin M, Noomen SP, van der Woude LH. Mechanical efficiency and propulsion technique after 7 weeks of low-intensity wheelchair training. Clin Biomech (Bristol, Avon). 2008;23(4):434-41. [PMID:18077065] http://dx.doi.org/10.1016/j.clinbiomech.2007.11.001

4. van der Woude LH, Bouw A, van Wegen J, van As H, Veeger D, de Groot S. Seat height: Effects on submaximal hand rim wheelchair performance during spinal cord injury rehabilitation. J Rehabil Med. 2009;41(3):143-49.

[PMID:19229446] http://dx.doi.org/10.2340/16501977-0296

5. van der Woude LH, Hendrich KM, Veeger HE, van Ingen Schenau GJ, Rozendal RH, de Groot G, Hollander AP. Manual wheelchair propulsion: Effects of power output on physiology and technique. Med Sci Sports Exerc. 1988; 20(1):70-78. [PMID:2963939]

http://dx.doi.org/10.1249/00005768-198802000-00011

6. Veeger HE, van der Woude LH, Rozendal RH. Effect of handrim velocity on mechanical efficiency in wheelchair propulsion. Med Sci Sports Exerc. 1992;24(1):100-107. [PMID:1548983] http://dx.doi.org/10.1249/00005768-199201000-00017

7. van der Linden ML, Valent L, Veeger HE, van der Woude LH. The effect of wheelchair handrim tube diameter on propulsion efficiency and force application (tube diameter and efficiency in wheelchairs). IEEE Trans Rehabil Eng. 1996;4(3):123-32. [PMID:8800215] http://dx.doi.org/10.1109/86.536767

8. Dallmeijer AJ, van der Woude LH, Veeger HE, Hollander AP. Effectiveness of force application in manual wheelchair propulsion in persons with spinal cord injuries. Am J Phys Med Rehabil. 1998;77(3):213-21.

\section{[PMID:9635556]}

9. Vegter RJ, Lamoth CJ, de Groot S, Veeger DH, van der Woude LH. Variability in bimanual wheelchair propulsion: Consistency of two instrumented wheels during handrim wheelchair propulsion on a motor driven treadmill. J Neuroeng Rehabil. 2013;10:9. [PMID:23360756] http://dx.doi.org/10.1186/1743-0003-10-9

10. Janssen TW, van Oers CA, van der Woude LH, Hollander AP. Physical strain in daily life of wheelchair users with spinal cord injuries. Med Sci Sports Exerc. 1994;26(6): 661-70. [PMID:8052104]

http://dx.doi.org/10.1249/00005768-199406000-00002

11. Boninger ML, Cooper RA, Robertson RN, Shimada SD. Three-dimensional pushrim forces during two speeds of wheelchair propulsion. Am J Phys Med Rehabil. 1997; 76(5):420-26. [PMID:9354497] http://dx.doi.org/10.1097/00002060-199709000-00013

12. Rodgers MM, McQuade KJ, Rasch EK, Keyser RE, Finley MA. Upper-limb fatigue-related joint power shifts in experienced wheelchair users and nonwheelchair users. J Rehabil Res Dev. 2003;40(1):27-37. [PMID:15150718] http://dx.doi.org/10.1682/JRRD.2003.01.0027

13. Ding D, Cooper RA. Electric-powered wheelchairs: A review of current technology and insight into future directions. IEEE Contr Syst Mag. 2005;25(2):22-34. http://dx.doi.org/10.1109/MCS.2005.1411382

14. Cooper RA, Corfman TA, Fitzgerald SG, Boninger ML, Spaeth DM, Ammer W, Arva J. Performance assessment of a pushrim activated power assisted wheelchair. IEEE Trans Contr Syst Technol. 2002;10(1):121-26. http://dx.doi.org/10.1109/87.974345

15. Kung YS, Wang MS, Yang CY. Realization of a motion control IC for electric-powered wheelchair. Proceedings of the 8th IEEE International Conference on Industrial Informatic; 2010 Jul 13-16; Osaka, Japan. p. 523-28.

16. Yang YP, Lin HC, Tsai FC, Lu CT, Tu KH. Design and integration of dual power wheels with rim motors for a powered wheelchair. IET Electric Power Appl. 2012;6(7): 419-28. http://dx.doi.org/10.1049/iet-epa.2011.0334

17. Phinyomark A, Phukpattaranont P, Limsaku C. A review of control methods for electric power wheelchairs based on electromyography signals with special emphasis on pattern recognition. IETE Tech Rev. 2011;28(4):316-26. http://dx.doi.org/10.4103/0256-4602.83552

18. Shibata T, Murakami T. Power-assist control of pushing task by repulsive compliance control in electric wheelchair. IEEE Trans Ind Electron. 2012;59(1):511-20. http://dx.doi.org/10.1109/TIE.2011.2146210

19. Wang FC, Chiang YS. Design and control of a PEMFC powered electric wheelchair. Int J Hydrogen Energy. 2012; 37(15):11299-11307. http://dx.doi.org/10.1016/j.ijhydene.2012.04.156

20. Lo HC, Tsai KH, Su FC, Yeh CY. Functional electrical stimulation cycling wheelchair for stroke patients: Design and preliminary evaluation results. J Med Biol Eng. 2011; 31(4):295-300. http://dx.doi.org/10.5405/jmbe. 857

21. Cooper RA. Engineering manual and electric powered wheelchairs. Crit Rev Biomed Eng. 1999;27(1-2):27-73. 


\section{[PMID:10638849]}

http://dx.doi.org/10.1615/CritRevBiomedEng.v27.i1-2.20

22. Fehr L, Langbein WE, Skaar SB. Adequacy of power wheelchair control interfaces for persons with severe disabilities: A clinical survey. J Rehabil Res Dev. 2000;37(3): 353-60. [PMID:10917267]

23. Tanimoto $\mathrm{T}$, inventor. Solar assist-type electric wheelchair. Japan Patent No. JP2004-167022, 2004.

24. Melanson D. Solar-powered wheelchair [Internet]. New York (NY): Engadget; 2006 Sep 1. Available from: http://www.engadget.com

25. Messenger S. Man to travel 200 miles in solar-powered wheelchair [Internet]. Toronto (Canada): Treehugger; 2010 Nov 21. http://www.treehugger.com/cars/man-to-travel200-miles-in-solar-powered-wheelchair.html

26. Curram AM, Ramana Rao PS, Dontikurti R. Solar powered wheel chair: Mobility for physically challenged. I J Curr Eng Technol. 2012;2(11):211-14.

27. Logan GD, Radcliffe DF. Potential for use of a House of Quality Matrix technique in rehabilitation engineering. IEEE Trans Rehabil Eng. 1997;5(1):106-15. [PMID:9086391] http://dx.doi.org/10.1109/86.559355

28. Karsak EE, Sozer S, Alptekin SE. Product planning in quality function deployment using a combined analytic network process and goal programming approach. Comput Ind Eng. 2003;44:171-90. http://dx.doi.org/10.1016/S0360-8352(02)00191-2

29. Evans JR, Lindsay WM. The management and control of quality. Saint Paul (MN): West Publishing; 1996.

30. Vairaktarakis GL. Optimization tools for design and marketing of new/improved products using the house of quality. J Oper Manage. 1999; 17:645-63. http://dx.doi.org/10.1016/S0272-6963(99)00020-0

31. Tsai KH, Yeh CY, Lo HC, Li CT, Cheng CP, Chang GL. Application of quality function deployment in design of mobile assistive devices. J Med Biol Eng. 2008;28(2):87-93.

32. Hauser JR, Clausing D. The house of quality. Harv Bus Rev. 1988;3:63-73.

33. Griffin A, Hauser JR. The voice of the customer. Mark Sci. 1993;12:1-27. http://dx.doi.org/10.1287/mksc.12.1.1

34. Yang SY. Study on damage mechanism of solar modules and practical power output of photovoltaic system [master's thesis]. [Tainen (Taiwan)]: Southern Taiwan University of Science and Technology; 2012.

35. International Organization for Standardization (ISO). Wheelchairs - Part 1: Determination of static stability. Geneva (Switzerland): ISO; 1999. ISO 7176-1:1999.

36. Americans with Disabilities Act and architectural barriers act accessibility guidelines. Washington (DC): United States Access Board; 2004.
37. Kuo TY, Lin TY, Tsai KH, Liao TY, inventors. A clutch to switch the operation mode of manual/electric wheelchairs, Taiwan patent I334347, 2010.

38. Cooper RA, Thorman T, Cooper R, Dvorznak MJ, Fitzgerald SG, Ammer W, Song-Feng G, Boninger ML. Driving characteristics of electric-powered wheelchair users: How far, fast, and often do people drive? Arch Phys Med Rehabil. 2002;83(2):250-55. [PMID:11833031] http://dx.doi.org/10.1053/apmr.2002.28020

39. Liu HY, Pearlman J, Cooper R, Hong EK, Wang H, Salatin $\mathrm{B}$, Cooper RA. Evaluation of aluminum ultralight rigid wheelchairs versus other ultralight wheelchairs using ANSI/RESNA standards. J Rehabil Res Dev. 2010;47(5): 441-55. [PMID:20803388] http://dx.doi.org/10.1682/JRRD.2009.08.0137

40. Rentschler AJ. Analysis of the ANSI/RESNA wheelchair standards: A comparison study of five different types of electric powered wheelchairs [master's thesis]. [Pittsburgh (PA)]: University of Pittsburgh; 2002. p. 25-38.

41. Cooper RA, VanSickle DP, Albright SJ, Stewart KJ, Flannery $\mathrm{M}$, Robertson RN. Power wheelchair range testing and energy consumption during fatigue testing. J Rehabil Res Dev. 1995;32(3):255-63. [PMID:8592297]

42. Pearlman JL, Cooper RA, Karnawat J, Cooper R, Boninger ML. Evaluation of the safety and durability of low-cost nonprogrammable electric powered wheelchairs. Arch Phys Med Rehabil. 2005;86(12):2361-70.

[PMID:16344036] http://dx.doi.org/10.1016/j.apmr.2005.07.294

43. Szeto AY, White RN. Evaluation of a curb-climbing aid for manual wheelchairs: Considerations of stability, effort, and safety. J Rehabil R D. 1983;20(1):45-56. [PMID:6887066]

44. Sauret C, Vaslin P, Lavaste F, de Saint Remy N, Cid M. Effects of user's actions on rolling resistance and wheelchair stability during handrim wheelchair propulsion in the field. Med Eng Phys. 2013;35(3):289-97. [PMID:11801413]

45. Cooper RA, Stewart KJ, VanSickle DP. Evaluation of methods for determining rearward static stability of manual wheelchairs. J Rehabil Res Dev. 1994;31(2):144-47. [PMID:7965871]

46. Kirby RL, Sampson MT, Thoren FA, MacLeod DA. Wheelchair stability: Effect of body position. J Rehabil Res Dev. 1995;32(4):367-72. [PMID:8770801]

47. de Groot S, Vegter RJ, van der Woude LH. Effect of wheelchair mass, tire type and tire pressure on physical strain and wheelchair propulsion technique. Med Eng Phys. 2013; 35(10):1476-82. [PMID:23642660]

http://dx.doi.org/10.1016/j.medengphy.2013.03.019

48. Bednarczyk JH, Sanderson DJ. Kinematics of wheelchair propulsion in adults and children with spinal cord injury. Arch Phys Med Rehabil. 1994;75(12):1327-34. [PMID:7993172] 
49. Sagawa Y Jr, Watelain E, Lepoutre FX, Thevenon A. Effects of wheelchair mass on the physiologic responses, perception of exertion, and performance during various simulated daily tasks. Arch Phys Med Rehabil. 2010;91(8): 1248-54. [PMID:20684906]

http://dx.doi.org/10.1016/j.apmr.2010.05.011

50. Cowan RE, Nash MS, Collinger JL, Koontz AM, Boninger ML. Impact of surface type, wheelchair weight, and axle position on wheelchair propulsion by novice older adults. Arch Phys Med Rehabil. 2009;90(7):1076-83. [PMID:19577019] http://dx.doi.org/10.1016/j.apmr.2008.10.034
Submitted for publication November 23, 2013. Accepted in revised form July 16, 2014.

This article and any supplementary material should be cited as follows:

Chien C, Huang T, Liao T, Kuo T, Lee T. Design and development of solar power-assisted manual/electric wheelchair. J Rehabil Res Dev. 2014;51(9):1411-26. http://dx.doi.org/10.1682/JRRD.2013.11.0250

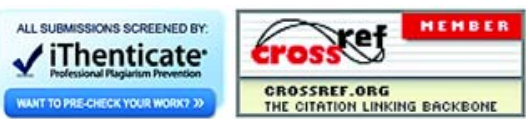


